\title{
Efeito do tamanho de partícula e da altura de corte de plantas de milho na dinâmica do processo fermentativo da silagem e no período de desensilagem ${ }^{1}$
}

\author{
Mikael Neumann², Paulo Roberto Frenzel Mühlbach ${ }^{3}$, José Laerte Nörnberg ${ }^{4}$, Paulo \\ Roberto Ost ${ }^{5}$, Sebastião Brasil Campos Lustosa ${ }^{6}$
}

\author{
1 Parte da tese de Doutorado do primeiro autor. \\ 2 NUPRAN (Núcleo de Produção Animal), Professor do Curso de Medicina Veterinária da UNICENTRO - Rua Simeão Camargo Varela de Sá, \\ 03, CEP: 85040-080, Centro de Ciências Agrárias e Ambientais da UNICENTRO, Guarapuava, PR. \\ ${ }^{3}$ Departamento de Zootecnia da UFRGS. \\ ${ }^{4}$ Departamento de Tecnologia de Alimentos da UFSM. \\ ${ }^{5}$ Departamento de Medicina Veterinária da UNICENTRO, Pesquisador do NUPRAN. \\ ${ }^{6}$ Departamento de Agronomia da UNICENTRO, Pesquisador do NUPRAN.
}

RESUMO - O experimento foi conduzido com o objetivo de avaliar o efeito do tamanho de partícula (pequeno: 0,2 a $0,6 \mathrm{~cm}$ ou grande: 1,0 a 2,0 cm) e da altura de corte de plantas de milho para ensilagem (baixa: $15 \mathrm{~cm}$ ou alta: $39 \mathrm{~cm}$ ) sobre a dinâmica do processo fermentativo das silagens e o período de desensilagem. Foram avaliados os seguintes tratamentos: silagem de partícula pequena com altura de corte baixa; silagem de partícula grande com altura de corte baixa; silagem de partícula pequena com altura de corte alta; e silagem de partícula grande com altura de corte alta. $\mathrm{O}$ delineamento experimental foi de blocos inteiramente casualizados com três repetições e parcelas subsubdivididas, em esquema fatorial $2 \times 2 \times 4$, composto de dois tamanhos de partículas (pequeno e grande), duas alturas de corte (baixa e alta) e quatro períodos de avaliação. Partículas pequenas determinaram maior eficiência de compactação da massa ensilada, diminuindo os gradientes de temperatura entre meio ambiente e silagem e o $\mathrm{pH}$ na desensilagem. As maiores deteriorações das silagens de milho ocorreram no estrato superior do silo, em decorrência da elevação da temperatura e dos maiores índices de pH e nitrogênio amoniacal desse estrato em relação ao inferior.

Palavras-chave: nitrogênio amoniacal, nível de compactação, pH, temperatura da silagem

\section{Effect of particle size and cutting height of corn on the dynamics of the silage fermentation process and feed-out period}

\begin{abstract}
The trial aimed to evaluate the effect of particle size (small: from 0.2 to $0.6 \mathrm{~cm}$ or large: from 1.0 to $2.0 \mathrm{~cm}$ ) and cutting height (low cut: $15 \mathrm{~cm}$ or high cut: $39 \mathrm{~cm}$ ) of the corn plant on the dynamics of the silage fermentation process and feed-out period. The treatments were: $T_{1}$ - small particle size with low cutting height; $T_{2}-$ large particle size with low cutting height; $\mathrm{T}_{3}$ - small particle size with high cutting height; and $\mathrm{T}_{4}$ - large particle size with high cutting height. A complete randomized blocks design with a factorial arrangement $(2 \times 2 \times 4)$ in a split-plot was used, with three replications. Factors evaluated were particle size (2), cutting height (2), and feed out evaluation periods (4). Small particle size improved compaction density and reduced temperature gradient between silage mass and environment and $\mathrm{pH}$ value of silage during feedout. Higher deterioration of corn silage occurred at the superior silo stratum, due to temperature elevation and higher $\mathrm{pH}$ index and ammoniacal nitrogen compared to inferior stratum.
\end{abstract}

Key Words: ammoniacal nitrogen, packing level, $\mathrm{pH}$, silage temperature

\section{Introdução}

No Brasil poucas pesquisas foram realizadas visando à quantificação das perdas absolutas na ensilagem e, na maior parte, esses resultados não representam a real situação do produtor, pois a maioria é conduzida utilizando-se de silos laboratoriais em condições que não refletem a realidade do processo. Em especial, não se dispõem de dados sistema- ticamente produzidos sobre as perdas durante a ensilagem e a desensilagem do material, as quais podem acrescentar até $20 \%$ de perdas adicionais no processo (McDonald et al., 1991).

A conservação de forragens na forma de silagem é um processo fermentativo anaeróbio que converte os carboidratos solúveis em ácidos orgânicos mediante atividade microbiana. A qualidade da silagem depende da 
eficiência deste processo fermentativo e das condições que a determinam: umidade, temperatura, presença de oxigênio, concentração de carboidratos solúveis e características particulares da composição físico-química da planta ensilada, podendo proporcionar a obtenção de silagens com variados valores nutritivos a partir de um mesmo tipo de forragem (Neumann, 2002a).

Com o corte da forragem, perdas quali e quantitativas ocorrem no material a ser ensilado, entre elas, as frações nitrogenadas via proteólise. Esse processo depende principalmente do $\mathrm{pH}$, do tempo de ensilagem, do conteúdo de matéria seca, da concentração de oxigênio e da temperatura (Mühlbach, 1999). Segundo Neumann (2002b), práticas simples, como o monitoramento dos índices de $\mathrm{pH}$ e da concentração de nitrogênio amoniacal $\left(\mathrm{N}^{-\mathrm{NH}_{3}} / \mathrm{NT}\right)$, podem ser bons indicadores das condições de fermentação da silagem e podem determinar de forma direta a identificação de silagens de boa aceitabilidade e consumo pelos animais.

De acordo com Evangelista et al. (2004), o pH e a umidade do ambiente são os principais fatores de supressão do crescimento clostridiano. Se a redução no valor de pH é muito lenta pode ocorrer desenvolvimento de clostrídios, dominando a fermentação decorrente e ocasionando perdas de matéria seca e energia e produção de ácido butírico, amônia e aminas, que determinarão menores taxas de consumo da silagem (Muck, 1988). O desenvolvimento dos clostrídios é restringido quando a forragem apresenta teores de MS superiores a $30 \%$ e pH inferior a 4,2 (Leinensperger \& Pitt, 1987).

Segundo McDonald et al. (1991), as alterações na composição das silagens são acompanhadas pelo aumento do $\mathrm{pH}$, da temperatura e da concentração de nitrogênio amoniacal. Logo, o monitoramento destas variáveis na desensilagem é importante para avaliar as perdas decorrentes da respiração das partículas, a atuação de microrganismos aeróbios (entre eles, as micotoxinas) e os processos de decomposição e/ou perdas por efluentes (Nussio et al., 2001). Segundo Mühlbach (1999), silagens de milho com qualidade adequada para alimentação de ruminantes devem apresentar $\mathrm{pH}$ abaixo de 4,0 e produção de nitrogênio amoniacal não superior a $10 \%$ do nitrogênio total para não ocasionar problemas de redução da palatabilidade e no consumo voluntário, proporcionando menores sobras de alimentos no cocho.

Este trabalho foi realizado com o objetivo de avaliar o efeito do tamanho de partícula (pequeno: 0,2 a $0,6 \mathrm{~cm}$ ou grande: 1,0 a 2,0 cm) e da altura de corte das plantas de milho na ensilagem (baixo: $15 \mathrm{~cm}$ ou alto: $39 \mathrm{~cm}$ ) na dinâmica do processo fermentativo e no período de desensilagem.

\section{Material e Métodos}

O experimento foi conduzido nas instalações do Núcleo de Produção Animal (NUPRAN) do Centro de Ciências Agrárias e Ambientais da Universidade Estadual do CentroOeste(UNICENTRO), em Guarapuava,PR, no período de 15 de outubro de 2004 a 15 de dezembro de 2005.

O clima da região de Guarapuava, PR é o Cfb (Subtropical mesotérmico úmido), sem estação seca, com verões frescos e inverno moderado, conforme classificação de Köppen, em altitude de aproximadamente $1.100 \mathrm{~m}$, com precipitação média anual de $1.944 \mathrm{~mm}$, temperatura média mínima anual de $12,7^{\circ} \mathrm{C}$, temperatura média máxima anual de $23,5^{\circ} \mathrm{C}$ e umidade relativa do ar de 77,9\%. O solo da área experimental, classificado como Latossolo Bruno Típico, apresenta as seguintes características químicas (perfil de 0 a $20 \mathrm{~cm}$ ): $\mathrm{pH}$ $\mathrm{CaCl}_{2}$ 0,01M: 4,7; P: $1,1 \mathrm{mg} \mathrm{dm}^{3-} ; \mathrm{K}^{+}: 0,2 \mathrm{cmol}_{\mathrm{c}} \mathrm{dm}^{3-} ; \mathrm{MO}$ : $2,62 \% ; \mathrm{Al}^{3+}: 0,0 \mathrm{cmol}_{\mathrm{c}} \mathrm{dm}^{3-} ; \mathrm{H}^{+}+\mathrm{Al}^{3+}: 5,2 \mathrm{cmol}_{\mathrm{c}} \mathrm{dm}^{3-}$; $\mathrm{Ca}^{2+}: 5,0 \mathrm{cmol}_{\mathrm{c}} \mathrm{dm}^{3-} ; \mathrm{Mg}^{2+}: 5,0 \mathrm{cmol}_{\mathrm{c}} \mathrm{dm}^{3-}$ e saturação de bases: $67,3 \%$.

Avaliou-se o efeito do tamanho de partícula (pequena: 0,2 a $0,6 \mathrm{~cm}$ ou grande: 1,0 a 2,0 cm) e da altura de corte das plantas de milho (baixo: $15 \mathrm{~cm}$ ou alto: $39 \mathrm{~cm}$ ) sobre a dinâmica do processo fermentativo das silagens e o período de desensilagem. Foram avaliadas quatro silagens: silagem de partícula pequena com altura de corte baixa; silagem de partícula grande com altura de corte baixa; silagem de partícula pequena com altura de corte alta; e silagem de partícula grande com altura de corte alta.

Como material experimental utilizaram-se silagens do híbrido de milho P-30S40, de caráter forrageiro de porte alto, produzidas em área de 2 ha, subdivida em 12 faixas de $1.700 \mathrm{~m}^{2}$. A lavoura foi estabelecida em 22 de outubro de 2004, em sistema de plantio direto com espaçamento entre linhas de $0,8 \mathrm{~m}$, profundidade de semeadura de $4 \mathrm{~cm} \mathrm{e}$ distribuição de 5 sementes $/ \mathrm{m}$.

A adubação de plantio constou de $350 \mathrm{~kg} / \mathrm{ha}$ da fórmula 08-30-20 ( $\left.\mathrm{N}-\mathrm{P}_{2} \mathrm{O}_{5}-\mathrm{K}_{2} \mathrm{O}\right)$, conforme Recomendações de Adubação e Calagem para os Estados do Rio Grande do Sul e Santa Catarina (1995). Após 35 dias do plantio, foi feita adubação em cobertura com $120 \mathrm{~kg} / \mathrm{ha}$ de N, na forma de uréia. No manejo da cultura até 30 dias após a emergência das plantas, foram aplicados herbicida (produto comercial Atrasina: $4 \mathrm{~L} / \mathrm{ha}$ ) + óleo mineral (produto comercial Assist: $1 \mathrm{~L} / \mathrm{ha}$ ) e defensivo para controle da lagarta do cartucho (produto comercial Karate: $150 \mathrm{~mL} / \mathrm{ha}$ ).

A colheita foi feita no estádio de grão pastoso nos dias 7 e 8 de março de 2005 utilizando-se ensiladeira. De forma alternada, seis faixas de cultivo de milho foram colhidas com 
regulagem em tamanho de partícula pequena e seis faixas em tamanho de partícula grande, alternando também a altura de corte (baixa ou alta) a cada três faixas.

O material colhido de cada faixa de cultivo foi transportado, depositado em local previamente nivelado e bem drenado, compactado com trator em silos (12 no total) do tipo semitrincheira, com 1,6 m de largura, $10 \mathrm{~m}$ de comprimento e $0,8 \mathrm{~m}$ de altura (capacidade individual de $8.000 \mathrm{~kg}$ ). Os silos foram completamente vedados e protegidos com lona de polietileno de três camadas $(200 \mu)$.

A abertura dos 12 silos foi realizada após 150 dias da ensilagem para coleta de amostras. Uma parte da amostra in natura foi prensada utilizando-se prensa hidráulica Carver, modelo C, para extração do suco. Parte deste suco, imediatamente após sua obtenção, foi utilizada para determinação do $\mathrm{pH}$, em potenciômetro digital, e do nitrogênio amoniacal, determinado em porcentagem do nitrogênio total $\left(\mathrm{N}-\mathrm{NH}_{3} / \mathrm{NT}\right)$, conforme técnica descrita pela AOAC (1995). Outra parte da amostra foi pesada, pré-seca em estufa de ar forçado a $55^{\circ} \mathrm{C}$ por 72 horas e triturada em moinho tipo Willey com peneira de malha de $1 \mathrm{~mm}$ para determinação do teor de matéria parcialmente seca.

Durante o período de desensilagem, foram realizadas diariamente (às 16h30) medições de temperatura do meio ambiente e da silagem nos estratos inferior e superior dos silos, em profundidade de $7 \mathrm{~cm}$ na massa estruturada na face dos silos.

A eficiência de compactação da massa $\left(\mathrm{kg} / \mathrm{m}^{3}\right)$ na base seca ou verde foi avaliada utilizando-se anel metálico de 10 $\mathrm{cm}$ de diâmetro e $15 \mathrm{~cm}$ de altura introduzido sob pressão nos estratos inferior e superior da massa estruturada da face dos silos para retirada, pesagem e amostragem de um volume definido de silagem compactada.

As variáveis foram determinadas conforme o estrato no silo $($ porção inferior $=$ profundidade de 0 a $40 \mathrm{~cm}$ ou porção superior $=$ profundidade de $40 \mathrm{a} 80 \mathrm{~cm}$ ) e o período de avaliação (quatro períodos: primeiro $=24 / 8$ a 14/9, segundo $=15 / 9$ a $5 / 10$, terceiro $=6 / 10$ a $26 / 10$ e quarto $=$ 27/10 a 16/11).

O experimento foi conduzido em delineamento de blocos inteiramente casualizados com três repetições utilizando-se parcelas sub-subdivididas, em esquema fatorial $2 \times 2 \times 4$, composto de dois tamanhos de partícula (pequeno: 0,2 a 0,6 $\mathrm{cm}$ ou grande: 1,0 a 2,0 cm), duas alturas de corte (baixo: 15 cm ou alto: $39 \mathrm{~cm})$ e quatro períodos de avaliação: primeiro (24/8 a 14/9), segundo (15/9 a 5/10), terceiro (6/10 a 26/10) e quarto (27/10 a 16/11), de modo que o efeito do tamanho de partículas foi alocado nas parcelas principais, referentes à altura de colheita (baixa e alta), estando o estrato no silo organizado em blocos (profundidade dos estratos do silo: inferior $=0$ a $40 \mathrm{~cm}$ e superior $=40 \mathrm{a} 80 \mathrm{~cm})$, e os períodos de avaliação durante a desensilagem (quatro tempos), nas subparcelas, designadas sistematicamente dentro das parcelas principais, conforme modelo estatístico descrito a seguir: $\mathrm{Y}_{\mathrm{ijk}}=\mu+\mathrm{TP}_{\mathrm{i}}+\mathrm{AC}_{\mathrm{j}}+(\mathrm{TP} * \mathrm{AC})_{\mathrm{ij}}+\mathrm{R}_{\mathrm{l}}(\mathrm{TP} * \mathrm{AC})_{\mathrm{ij}}+\mathrm{P}_{\mathrm{k}}$ $+(\mathrm{TP} * \mathrm{P})_{\mathrm{ik}}+(\mathrm{AC} * \mathrm{P})_{\mathrm{ik}}+\left(\mathrm{TP} * \mathrm{AC} * \mathrm{D}^{*}\right)_{\mathrm{ijk}}+\mathrm{LS}_{1}+(\mathrm{TP} * \mathrm{LS})_{\mathrm{il}}$ $+(\mathrm{AC} * \mathrm{LS})_{\mathrm{il}}+(\mathrm{TP} * \mathrm{AC} * \mathrm{LS} *)_{\mathrm{ijl}}+(\mathrm{P} * \mathrm{LS})_{\mathrm{kl}}+(\mathrm{TP} * \mathrm{P} * \mathrm{LS})_{\mathrm{jk} 1}$ $+(\mathrm{AC} * \mathrm{P} * \mathrm{LS})_{\mathrm{ikl}}+\mathrm{E}_{\mathrm{ijklm}}$, em que: $\mathrm{Y}_{\mathrm{ijkl}}=$ variáveis dependentes; $\mu=$ média geral de todas as observações; $\mathrm{TP}_{\mathrm{i}}=$ efeito do tamanho da partícula da silagem de ordem "i”: 1 = pequena e 2 = grande; $\mathrm{AC}_{\mathrm{j}}=$ efeito da altura de colheita de ordem “ $\mathrm{j}$ ”: 1 = baixa e 2 = alta; $(\mathrm{TP} * \mathrm{AC})_{\mathrm{ij}}=$ efeito da interação i-ésimo tamanho de partícula $\times \mathrm{j}$-ésima altura de colheita; $\mathrm{R}_{1}(\mathrm{TP} * \mathrm{AC})_{\mathrm{ij}}=$ efeito aleatório baseado na repetição dentro da combinação $(\mathrm{TP} * \mathrm{AC})_{\mathrm{ij}}$ (Erro a); $\mathrm{P}_{\mathrm{k}}=$ efeito do período de coleta de amostras de silagem durante a desensilagem de ordem " $\mathrm{k}$ ": 1 = primeiro período, 2 = segundo período, 3 = terceiro período e 4 = quarto período; $(\mathrm{TP} * \mathrm{P})_{\mathrm{ik}}=$ efeito da interação i-ésimo tamanho de partícula $\times \mathrm{k}$-ésimo período de coleta na desensilagem; $(\mathrm{AC} * \mathrm{P})_{\mathrm{ik}}=$ efeito da interação $\mathrm{j}$-ésima altura de colheita $\times \mathrm{k}$-ésimo período de coleta de amostras de silagem na desensilagem; $\left(\mathrm{TP}^{*} \mathrm{AC} * \mathrm{P} *\right)_{\mathrm{ijk}}=$ efeito da interação i-ésimo tamanho de partícula $\times$ j-ésima altura de colheita $\times$ k-ésimo período de coleta de amostras de silagem na desensilagem; $\mathrm{LS}_{1}=$ efeito do estrato no silo de ordem "l": 1 = estrato inferior e 2 = estrato superior; $(\mathrm{TP} * \mathrm{LS})_{\mathrm{il}}=$ efeito da interação i-ésimo tamanho de partícula $\times$ 1-ésimo estrato no silo; $(\mathrm{AC} * \mathrm{LS})_{\mathrm{il}}=$ efeito da interação j-ésima altura de colheita $\times$ 1-ésimo estrato no silo; $(\mathrm{TP} * \mathrm{AC} * \mathrm{LS} *)_{\mathrm{ijl}}=$ efeito da interação i-ésimo tamanho de partícula $\times \mathrm{j}$-ésima altura de colheita $\times 1$-ésimo estrato no silo; $\left(\mathrm{P}^{*} \mathrm{LS}\right)_{\mathrm{k} 1}=$ efeito da interação k-ésimo período de coleta na desensilagem $\times$ 1-ésimo estrato no silo; $(\mathrm{TP} * \mathrm{P} * \mathrm{LS})_{\mathrm{jkl}}=$ efeito da interação i-ésimo tamanho de partícula $\times$ k-ésimo período de coleta de amostras de silagem na desensilagem $\times 1$-ésimo estrato no silo; $(\mathrm{AC} * \mathrm{P} * \mathrm{LS})_{\mathrm{ikl}}=$ efeito da interação j-ésima altura de colheita $\times$ k-ésimo período de coleta de amostras de silagem na desensilagem $\times$ l-ésimo estrato no silo; e $\mathrm{E}_{\mathrm{ijkl}}=$ efeito aleatório residual (Errob).

Os dados coletados para cada variável foram submetidos à análise de variância, por meio do programa estatístico SAS (1993), e as diferenças entre as médias foram analisadas pelo teste Tukey a 5\% de significância.

A interação $\left(\mathrm{TP}^{*} \mathrm{AC} * \mathrm{P} * \mathrm{LS}\right)_{\mathrm{ijkl}}$ inicialmente foi testada, no entanto, em virtude da baixa magnitude, foi removida do modelo estatístico. Os dados também foram submetidos à análise de regressão polinomial, considerando o período (84 dias), por meio do procedimento "proc reg" do programa SAS (SAS, 1993). 


\section{Resultados e Discussão}

A interação altura de colheita $\times$ tamanho de partícula influenciou o teor de MS do painel do silo e o nível de compactação na base verde, mas não afetou o nível de compactação na base seca (Tabela 1).

O tamanho da partícula ensilada, em nível prático, se relacionou diretamente com a potência do trator e/ou a regulagem da ensiladeira utilizada. O menor tamanho de partícula facilitou o processo de ensilagem, pois permitiu maior densidade de transporte do material colhido até o local de armazenamento e ainda aumentou a eficiência de compactação permitindo melhor fermentação anaeróbia (Tabela 5). Conseqüentemente, houve melhor preservação do valor nutritivo da massa ensilada e minimização das perdas na desensilagem (Tabelas 6 e 7).

Os teores de MS das silagens diferiram entre os processos de colheita das plantas (Tabela 1). Silagens de milho colhido à altura de $30 \mathrm{~cm}$ e com partículas pequenas apresentaram maiores teores de matéria seca $(28,67 \%)$ em comparação à de milho colhido com altura de corte alta e partícula grande (26,24\%), no entanto, ambas não diferiram das silagens de corte baixo com partícula pequena ou

Tabela 1 - Teor de MS e eficiência de compactação na base verde e na base seca das silagens de milho

Table 1 - DM concentration and compactness efficiency of silages, on fresh matter and dry matter basis of corn silages

\begin{tabular}{|c|c|c|c|}
\hline \multirow[t]{2}{*}{$\begin{array}{l}\text { Tamanho de partícula } \\
\text { Particle size }\end{array}$} & \multicolumn{2}{|c|}{$\begin{array}{l}\text { Altura de colheita } \\
\text { Cutting height }\end{array}$} & \multirow[t]{2}{*}{$\begin{array}{l}\text { Média } \\
\text { Mean }\end{array}$} \\
\hline & $\begin{array}{l}\text { Corte baixo } \\
\text { Low cutting }\end{array}$ & $\begin{array}{l}\text { Corte alto } \\
\text { High cutting }\end{array}$ & \\
\hline & \multicolumn{2}{|c|}{$\begin{array}{c}\text { Matéria seca da silagem, } \% \\
\text { Dry matter of silage, \% }\end{array}$} & \\
\hline Pequeno (Small) & $28,11 \mathrm{ab}$ & $28,67 \mathrm{a}$ & 28,39 \\
\hline Grande (Large) & $27,43 a b$ & $26,24 b$ & 26,83 \\
\hline \multirow[t]{2}{*}{ Média (Mean) } & 27,77 & 27,45 & \\
\hline & \multicolumn{2}{|c|}{$\begin{array}{l}\text { Compactação base verde, } \mathrm{kg} / \mathrm{r} \\
\text { Fresh matter compactness, } \mathrm{kg} / \mathrm{m}^{3}\end{array}$} & \\
\hline Pequeno (Small) & $554,1 \mathrm{a}$ & $524,2 \mathrm{ab}$ & 539,1 \\
\hline Grande (Large) & $404,4 \mathrm{c}$ & $447,9 \mathrm{bc}$ & 426,1 \\
\hline \multirow[t]{2}{*}{ Média (Mean) } & 479,2 & 486,1 & \\
\hline & \multicolumn{2}{|c|}{$\begin{array}{c}\text { Compactação base seca, } \mathrm{kg} / \mathrm{m} \\
\text { Dry matter compactness, } \mathrm{kg} / \mathrm{m}^{3}\end{array}$} & \\
\hline Pequeno (Small) & 154,5 & 151,1 & $152,8 \mathrm{~A}$ \\
\hline Grande (Large) & 111,1 & 117,8 & $114,4 \mathrm{~B}$ \\
\hline Média (Mean) & $132,8 \mathrm{~A}$ & $134,4 \mathrm{~A}$ & \\
\hline
\end{tabular}

Médias seguidas por letras minúsculas diferentes diferem entre si $(P<0,05)$ pelo teste Tukey.

Médias na linha ou na coluna seguidas por letras maiúsculas diferentes diferem $(P<0,05)$ pelo teste $F$.

Means followed by different small letters, are different $(P<0.05)$ by Tukey test.

Means, within a row or a column, followed by different capital letters are different

$(P<0.05)$ by F test. grande. A compactação da silagem, na base verde, foi melhor $(\mathrm{P}<0,05)$ quando a forragem foi colhida a $15 \mathrm{~cm}$ de altura com partículas pequenas $\left(554,1 \mathrm{~kg} / \mathrm{m}^{3}\right)$ em relação à forragem colhida a 15 ou $30 \mathrm{~cm}$ de altura com partículas grandes, no entanto, não diferiu $(\mathrm{P}>0,05)$ da silagem colhida a $30 \mathrm{~cm}$ com partículas pequenas. Na avaliação do processo de compactação, na base seca, silagens com partículas pequenas tiveram maior eficiência de $33,6 \%$ em relação às de partículas grandes $\left(152,8 \mathrm{vs} 114,4 \mathrm{~kg} / \mathrm{m}^{3}\right.$ de MS).

Segundo Balsalobre et al. (2001), o uso de partículas pequenas na confecção de silagens define menores custos de produção e promovem menores perdas físicas durante a retirada e distribuição da silagem no cocho, associadas, neste caso, ao tipo de sistema de desensilagem. Senger et al. (2005) afirmaram que o material original deve ser bem compactado (nível de compactação superior a $650 \mathrm{~kg} / \mathrm{m}^{3} \mathrm{de}$ MV) objetivando condição anaeróbia à fermentação a fim de que as características qualitativas da silagem sejam bastante

Tabela 2 - Teor de MS e eficiência de compactação na base verde e na base seca das silagens de milho

Table 2 - DM concentration and efficiency of silage compactness, on fresh matter and DM basis of corn silages

\begin{tabular}{|c|c|c|c|c|}
\hline \multirow[t]{2}{*}{$\begin{array}{l}\text { Estrato } \\
\text { Stratum }\end{array}$} & \multirow{2}{*}{$\begin{array}{c}\text { Tamanho de partícul } \\
\text { Particle size }\end{array}$} & \multicolumn{2}{|c|}{$\begin{array}{l}\text { Altura de colheita } \\
\text { Cutting height }\end{array}$} & \multirow[t]{2}{*}{$\begin{array}{l}\text { Média } \\
\text { Mean }\end{array}$} \\
\hline & & $\begin{array}{l}\text { Corte baixo } \\
\text { Low cutting }\end{array}$ & $\begin{array}{l}\text { Corte alto } \\
\text { High cutting }\end{array}$ & \\
\hline & & \multicolumn{2}{|c|}{$\begin{array}{c}\text { Matéria seca da silagem, \% } \\
\text { Silage dry matter, } \%\end{array}$} & \\
\hline \multirow[t]{3}{*}{ Inferior } & Pequeno (Small) & 27,72 & 29,02 & 28,37 \\
\hline & Grande (Large) & 26,89 & 26,34 & 26,61 \\
\hline & Média (Mean) & 27,30 & 27,68 & $27,50 \mathrm{~A}$ \\
\hline \multirow[t]{4}{*}{ Superior } & Pequeno (Small) & 28,50 & 28,33 & 28,41 \\
\hline & Grande (Large) & 27,97 & 26,15 & 27,06 \\
\hline & Média (Mean) & 28,24 & 27,24 & $27,73 \mathrm{~A}$ \\
\hline & \multicolumn{4}{|c|}{$\begin{array}{l}\text { Compactação base verde, } \mathrm{kg} / \mathrm{m}^{3} \\
\text { Fresh matter compactness, } \mathrm{kg} / \mathrm{m}^{3}\end{array}$} \\
\hline \multirow[t]{3}{*}{ Inferior } & Pequeno (Small) & 619,3 & 571,6 & 595,5 \\
\hline & Grande (Large) & 439,0 & 501,5 & 470,3 \\
\hline & Média (Mean) & 529,1 & 536,6 & $532,9 \mathrm{~A}$ \\
\hline \multirow[t]{4}{*}{ Superior } & Pequeno (Small) & 489,0 & 476,8 & 482,9 \\
\hline & Grande (Large) & 369,8 & 394,3 & 382,0 \\
\hline & Média (Mean) & 429,4 & 435,5 & $432,5 \mathrm{~B}$ \\
\hline & \multicolumn{4}{|c|}{$\begin{array}{c}\text { Compactação base seca, } \mathrm{kg} / \mathrm{m}^{3} \\
\text { DM compactness, } \mathrm{kg} / \mathrm{m}^{3}\end{array}$} \\
\hline \multirow[t]{3}{*}{ Inferior } & Pequeno (Small) & 170,7 & 166,7 & 168,7 \\
\hline & Grande (Large) & 118,4 & 132,2 & 125,3 \\
\hline & Média (Mean) & 144,5 & 149,5 & $147,0 \mathrm{~A}$ \\
\hline \multirow[t]{3}{*}{ Superior } & Pequeno (Small) & 138,4 & 135,4 & 136,9 \\
\hline & Grande (Large) & 103,9 & 103,5 & 103,7 \\
\hline & Média (Mean) & 121,1 & 119,4 & $120,3 \mathrm{~B}$ \\
\hline
\end{tabular}

Médias na coluna seguidas de letras maiúsculas diferentes diferem $(P<0,05)$ pelo teste $F$.

Means within a column followed by different capital letters are different $(P<0.05)$ by $F$ test 
similares às do material original, pois, segundo Mulligan et al. (2002), silagens mal compactadas (nível de compactação inferior a $300 \mathrm{~kg} / \mathrm{m}^{3}$ de MV) determinam maior atividade de enzimas proteolíticas que transformam o nitrogênio protéico em formas de NNP (peptídios e aminoácidos livres), onde seqüencialmente bactérias proteolíticas, via fermentação, transformam estes elementos em diversos ácidos orgânicos, $\mathrm{CO}_{2}$, amônia e aminas, produtos associados à redução do consumo das silagens pelos animais.

Senger et al. (2005), avaliando silagens de milho com diferentes teores de umidade e níveis de compactação, concluíram que silagens com maior teor de matéria seca (>28\%) e bem compactadas ( $>650 \mathrm{~kg} / \mathrm{m}^{3}$ de MV) preservam maior quantidade de açúcares, que podem ser usados como fonte de energia por microrganismos ruminais, além de apresentarem menor relação FDN/CNF e serem mais digestíveis.

Não houve diferença $(\mathrm{P}>0,05)$ entre estratos no silo quanto ao teor de MS da silagem no painel do silo (Tabela 2). Na média geral, o estrato superior apresentou menor $(\mathrm{P}<0,05)$ eficiência de compactação em relação ao inferior $(432,5$ vs $532,9 \mathrm{~kg} / \mathrm{m}^{3}$ de MV e 120,3 vs $147,0 \mathrm{~kg} / \mathrm{m}^{3}$ de MS), o que favoreceu a permanência de oxigênio proporcionando a respiração das partículas, diminuindo a concentração de compostos solúveis e energia e limitando também o crescimento microbiano.

A compactação (ECMS) da silagem, na base seca, e o período de desensilagem tiveram efeito linear sobre o teor de $\mathrm{MS}(\mathrm{MS}=28,8954-0,0244 \mathrm{D}$ e $\mathrm{ECMS}=160,1521-$ $0,5048 \mathrm{D}$, respectivamente), que diminuiu em $0,0244 \% \mathrm{e}$ $0,05048 \mathrm{~kg} / \mathrm{m}^{3}$ a cada dia após abertura do silo (Tabela 3 ).

Loures et al. (2003), avaliando as perdas em silagens de capim-elefante produzidas com diferentes níveis de compactação, evidenciaram, em silos de PVC, que tanto o teor de umidade quanto a eficiência de compactação alteraram conforme o estrato no silo, de modo que o teor de umidade e a compactação foram melhores na parte inferior do silo. Esses autores notaram efeito quadrático dos níveis de compactação (300 a $800 \mathrm{~kg} / \mathrm{m}^{3}$ de MV) sobre os valores de FDN e FDA, que foram menores nas densidades de 518,3 e $585,5 \mathrm{~kg} / \mathrm{m}^{3}$, como resultado da ocorrência de reações de Maillard, que produziram componentes insolúveis em detergente ácido, determinados pelas reações dos açúcares e glicídios aos aminoácidos presentes na massa ensilada provocando aumentos também nos teores de FDN e redução dos coeficientes de digestibilidade. Loures et al. (2003) sugeriram que em densidades de $800 \mathrm{~kg} / \mathrm{m}^{3}$, o aumento nos teores de FDN e FDA estariam relacionados ao maior consumo dos constituintes passíveis de serem solubilizados na MS, como os carboidratos solúveis e minerais, pela ação dos microrganismos fermentadores e/ou pela ocorrência de lixiviação ao longo do processo de ensilagem, seguindo-se a fermentação.

Houve interação significativa $(\mathrm{P}<0,05)$ período de desensilagem $\times$ estrato no silo, enquanto as demais combinações envolvendo o fator período não foram significativas $(P>0,05)$ para o diferencial entre meio ambiente $\mathrm{e}$ silagem (DTSA) e para a temperatura da silagem (TS) (Tabela 4). O diferencial de temperatura entre a silagem contida no estrato inferior do silo e o ambiente durante os períodos de desensilagem sofreu efeito quadrático do sistema de ensilagem $\left(\mathrm{DTI}=9,5677-0,1480 \mathrm{D}+0,0012 \mathrm{D}^{2}\right)$, com ponto de mínimo diferencial de temperatura de $5^{\circ} \mathrm{C}$ aos 61,7 dias de uso do silo, enquanto, no estrato superior, também sob efeito quadrático $\left(16,9902-0,3628 \mathrm{D}+0,0031 \mathrm{D}^{2}\right)$, o ponto de mínimo diferencial de temperatura foi de $6,37^{\circ} \mathrm{C}$ aos 58,52 dias de uso do silo. A temperatura da massa ensilada no estrato inferior apresentou tendência linear ( TI $=23,4063+0,0655 \mathrm{D})$, aumentando em $0,0655^{\circ} \mathrm{C}$ a cada dia após abertura do silo, enquanto, no estrato superior, o comportamento foi quadrático $(\mathrm{TS}=33,9867-0,3017 \mathrm{D}+$ $\left.0,0033 \mathrm{D}^{2}\right)$, com ponto de mínima temperatura de $27,09^{\circ} \mathrm{C}$ aos 45,71 dias de uso do silo.

A temperatura é um fator físico que afeta a taxa de deterioração da silagem, pois seu aumento está diretamente relacionado à oxidação da matéria seca provocando perdas na forma de dióxido de carbono (Hill \& Leaver, 2002). A temperatura da silagem é resultado do balanço entre a taxa de calor produzida pela atividade microbiana e as perdas de calor por condução, radiação, evaporação e convecção. Segundo Willians et al. (1997), o balanço final de energia fornece calor para o crescimento microbiano até níveis ótimos para seu desenvolvimento. Esses autores, estudando a estabilidade aeróbia de silagens, observaram mudanças significativas da temperatura após sete dias de aeração. Entretanto, Hill \& Leaver (2002), obtiveram aumento de temperatura e produção de $\mathrm{CO}_{2}$ até dez dias de exposição aeróbia da silagem, juntamente com o aumento da atividade microbiana. Depois desse período, ocorreu diminuição da temperatura e produção de $\mathrm{CO}_{2}$, o que pode estar relacionado aos processos limitantes da colonização microbiana, ocasionada pela diminuição do fornecimento de fontes disponíveis de carbono e nitrogênio.

De acordo com dados apresentados por Nussio et al. (2002), silagens com aproximadamente $30 \%$ de MS apresentam maiores teores de ácido lático e são mais instáveis após a abertura com o aumento da MS, em virtude da alta possibilidade de ocorrência de deterioração aeróbia, associada a 
Tabela 3 - Teor médio de MS e eficiência de compactação, na base verde e seca das silagens de milho Table 3 - DM concentration and efficiency of silage compactness, on fresh matter and dry matter basis of corn silages

\begin{tabular}{|c|c|c|c|c|c|c|}
\hline \multirow[t]{2}{*}{$\begin{array}{l}\text { Estrato } \\
\text { Stratum }\end{array}$} & \multirow[t]{2}{*}{$\begin{array}{c}\text { Tamanho de partícula } \\
\text { Particle size }\end{array}$} & \multirow[t]{2}{*}{$\begin{array}{l}\text { Altura de corte } \\
\text { Cutting height }\end{array}$} & \multicolumn{4}{|c|}{$\begin{array}{l}\text { Período de desensilagem } \\
\text { Feed-out period }\end{array}$} \\
\hline & & & $\begin{array}{l}24 / 8 \text { a } 14 / 9 \\
8 / 24 \text { to } 9 / 14\end{array}$ & $\begin{array}{l}15 / 9 \text { a } 5 / 10 \\
9 / 15 \text { to } 10 / 5\end{array}$ & $\begin{array}{c}6 / 10 \text { a } 26 / 10 \\
10 / 6 \text { to } 10 / 26\end{array}$ & $\begin{array}{c}27 / 10 \text { a } 16 / 11 \\
10 / 27 \text { to } 11 / 16\end{array}$ \\
\hline \multirow{6}{*}{ Inferior } & & & \multicolumn{4}{|c|}{$\begin{array}{c}\text { Matéria seca da silagem, } \% \\
\text { Dry matter of silage, \% }\end{array}$} \\
\hline & Pequeno (Small) & Baixa (Low) & 27,97 & 26,59 & 27,58 & 28,73 \\
\hline & Grande (Large) & Baixa (Low) & 29,07 & 26,43 & 26,85 & 25,21 \\
\hline & Pequeno (Small) & Alta (High) & 28,92 & 28,83 & 29,18 & 29,16 \\
\hline & Grande (Large) & Alta (High) & 26,64 & 26,42 & 27,12 & 25,17 \\
\hline & Média (Mean) & & 28,15 & 27,07 & 27,68 & 27,07 \\
\hline \multirow{5}{*}{ Superior } & Pequeno (Small) & Baixa (Low) & 29,81 & 28,06 & 29,00 & 27,12 \\
\hline & Grande (Large) & Baixa (Low) & 29,18 & 28,65 & 27,83 & 26,22 \\
\hline & Pequeno (Small) & Alta (High) & 29,01 & 28,53 & 28,23 & 27,53 \\
\hline & Grande (Large) & Alta (High) & 27,47 & 26,39 & 26,29 & 24,49 \\
\hline & Média (Mean) & & 28,87 & 27,91 & 27,84 & 26,34 \\
\hline \multicolumn{7}{|c|}{ Equação regressão*: MS $(D M)=28,8954-0,0244 \mathrm{D}\left(\mathrm{R}^{2}: 0,0880 ; \mathrm{CV}: 6,75 \% ; \mathrm{P}<0,0033\right)$} \\
\hline \multirow{6}{*}{ Inferior } & & & \multicolumn{4}{|c|}{$\begin{array}{l}\text { Compactação base verde, } \mathrm{kg} / \mathrm{m}^{3} \\
\text { Green matter compactness, } \mathrm{kg} / \mathrm{m}^{3}\end{array}$} \\
\hline & Pequeno (Small) & Baixa (Low) & 654,0 & 648,2 & 693,5 & 481,5 \\
\hline & Grande (Large) & Baixa (Low) & 548,2 & 435,5 & 417,1 & 355,4 \\
\hline & Pequeno (Small) & Alta (High) & 637,5 & 620,2 & 545,5 & 483,4 \\
\hline & Grande (Large) & Alta (High) & 512,9 & 544,0 & 521,7 & 527,4 \\
\hline & Média (Mean) & & 588,1 & 562,0 & 544,4 & 461,9 \\
\hline \multirow{5}{*}{ Superior } & Pequeno (Small) & Baixa (Low) & 409,4 & 544,7 & 584,6 & 417,5 \\
\hline & Grande (Large) & Baixa (Low) & 435,1 & 404,4 & 324,3 & 315,5 \\
\hline & Pequeno (Small) & Alta (High) & 468,1 & 525,9 & 503,3 & 409,8 \\
\hline & Grande (Large) & Alta (High) & 378,7 & 415,2 & 433,9 & 349,2 \\
\hline & Média (Mean) & & 422,8 & 472,5 & 461,5 & 373,0 \\
\hline \multicolumn{7}{|c|}{ Equação regressão: $\mathrm{ECMV}=424,3542+5,0340 \mathrm{D}-0,0623 \mathrm{D}^{2}\left(\mathrm{R}^{2}: 0,1384 ; \mathrm{CV}: 13,50 \% ; \mathrm{P}<0,0010\right)$} \\
\hline \multirow{6}{*}{ Inferior } & & & \multicolumn{4}{|c|}{$\begin{array}{c}\text { Compactação base seca, } \mathrm{kg} / \mathrm{m}^{3} \\
\text { Dry matter compactness, } \mathrm{kg} / \mathrm{m}^{3}\end{array}$} \\
\hline & Pequeno (Small) & Baixa (Low) & 183,0 & 170,4 & 191,0 & 138,3 \\
\hline & Grande (Large) & Baixa (Low) & 158,0 & 115,2 & 111,2 & 89,2 \\
\hline & Pequeno (Small) & Alta (High) & 184,0 & 180,3 & 160,6 & 141,9 \\
\hline & Grande (Large) & Alta (High) & 136,7 & 143,5 & 141,5 & 107,3 \\
\hline & Média (Mean) & & 165,4 & 152,3 & 151,1 & 119,2 \\
\hline \multirow{5}{*}{ Superior } & Pequeno (Small) & Baixa (Low) & 121,4 & 150,0 & 168,9 & 113,1 \\
\hline & Grande (Large) & Baixa (Low) & 126,7 & 115,4 & 90,7 & 82,7 \\
\hline & Pequeno (Small) & Alta (High) & 135,5 & 150,3 & 142,9 & 112,9 \\
\hline & Grande (Large) & Alta (High) & 103,9 & 109,7 & 114,6 & 85,8 \\
\hline & Média (Mean) & & 121,9 & 131,3 & 129,3 & 98,6 \\
\hline
\end{tabular}

* $\mathrm{D}=$ período de desensilagem de 1 a 84 dias ( $D=$ Feed-out period of 1 to 84 days).

aumento da temperatura, perdas de MS e crescimento de fungos na superfície do silo. Fatores como alto teor de carboidratos solúveis, baixo teor de ácido acético e presença de leveduras, acompanhados de compactação insuficiente da massa, contribuem para diminuição da estabilidade aeróbia da silagem. Desse modo, as práticas rotineiramente recomendadas para adequada fermentação da silagem visando máxima conservação de energia (carboidratos) podem proporcionar silagens mais instáveis às condições de exposição aeróbia quando ocorre a abertura do silo.

O balanço da temperatura indicou aumento crescente na temperatura durante a exposição aeróbia nos diferentes períodos de desensilagem (Tabela 4). Em temperaturas ambientes maiores, a elevação da temperatura tende a ser maior, uma vez que a temperatura é considerada um ativador das reações químicas e microbiológicas. 
Tabela 4 - Diferencial de temperatura entre silagem e ambiente (DTSA) e temperatura (TS) das silagens de milho Table 4 - Temperature difference between silage and environment (TDSE) and temperature (ST) of corn silages

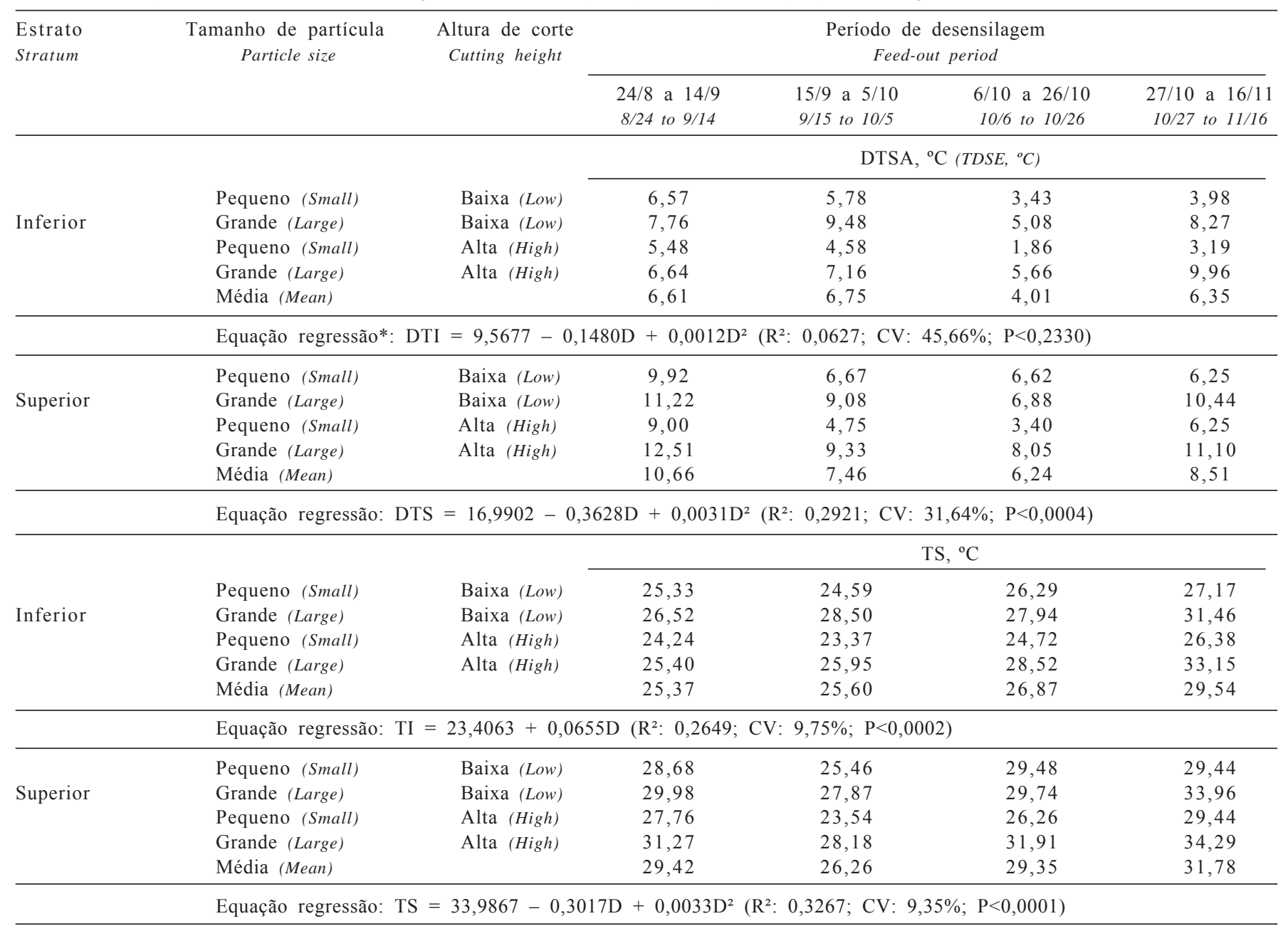

* $\mathrm{D}=$ período de desensilagem de 1 a 84 dias $(D=$ Feed-out period of 1 to 84 days).

Também foram observadas interações significativas $(\mathrm{P}<0,05)$ entre período de desensilagem e tamanho de partícula para as variáveis DTSA e TS, que, na silagem com tamanho de partículas grandes durante os períodos de desensilagem, sofreram, respectivamente, efeito quadrático $\left(\mathrm{DTSAG}=14,3144-0,2611 \mathrm{D}+0,0024 \mathrm{D}^{2}, \mathrm{R}^{2}: 0,1599 ; \mathrm{CV}\right.$ : $29,54 \% ; \mathrm{P}<0,0198$ e TSG $=31,2671-0,1968 \mathrm{D}+0,0026 \mathrm{D}^{2}, \mathrm{R}^{2}$ : $0,4561 ; \mathrm{CV}: 8,27 \% ; \mathrm{P}<0,0001)$, componto de mínimo diferencial de temperatura entre a silagem e ambiente de $7,21^{\circ} \mathrm{C}$ aos 54,40 dias e de mínima temperatura de $27,54^{\circ} \mathrm{C}$ aos 37,85 dias de uso do silo. Na silagem com tamanho de partículas pequeno $\left(\mathrm{DTSAP}=12,2435-0,2497 \mathrm{D}+0,0019 \mathrm{D}^{2}, \mathrm{R}^{2}\right.$ : 0,$3049 ; \mathrm{CV}: 40,15 \% ; \mathrm{P}<0,0003$ e TSP $=29,1748-0,1847 \mathrm{D}+$ $\left.0,0021 D^{2}, R^{2}: 0,2346 ; C V: 8,67 \% ; P<0,0024\right)$, o ponto de mínimo diferencial foi de $4,04^{\circ} \mathrm{C}$ aos 65,71 dias e o de mínima temperatura foi de $25,11^{\circ} \mathrm{C}$ aos 43,98 dias de uso.

Não houve interação significativa $(\mathrm{P}>0,05)$ período de desensilagem $\times$ altura de colheita $\times$ tamanho de partícula $\times$ estrato no silo para as variáveis $\mathrm{pH}$ e $\mathrm{N}-\mathrm{NH}_{3} / \mathrm{NT}$.
Não houve interação significativa simples ou combinada do período de desensilagem e os fatores tamanho de partícula, altura de colheita e estrato no silo para DTSA, TS (Tabela 4),

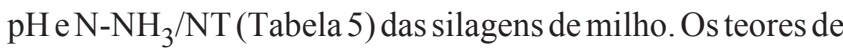
$\mathrm{N}-\mathrm{NH}_{3} / \mathrm{NT}$ não diferiram entre os períodos de desensilagem $(2,54 \%)$, mas os valores de $\mathrm{pH}$ da silagem aumentaram de forma linear do primeiro ao $84^{\circ}$ dia a uma taxa diária de 0,0085 .

Os teores de $\mathrm{N}-\mathrm{NH}_{3} / \mathrm{NT}(\mathrm{P}<0,05)$ observados na silagem de partícula pequena $(2,79 \%)$ foram maiores que os obtidos na silagem de partículas grandes $(2,28 \%)$. O conteúdo de $\mathrm{N}-\mathrm{NH}_{3} / \mathrm{NT}$ é importante na determinação da qualidade da silagem, pois, segundo Guim et al. (2002), as mudanças na qualidade da silagem afetam primeiramente o conteúdo de $\mathrm{N}-\mathrm{NH}_{3}$ da silagem e estas mudanças são acompanhadas pelas mudanças de pH e ácidos orgânicos. Pode-se afirmar que as silagens em estudo foram bem conservadas durante o período de armazenamento, pois na abertura dos silos apresentaram valores baixos de $\mathrm{N}-\mathrm{NH}_{3}$ (abaixo de $10 \%$ do NT), conforme parâmetros citados por Tosi et al. (1999). 
Tabela 5 - Índices de $\mathrm{pH}$ e teores de $\mathrm{N}-\mathrm{NH}_{3} / \mathrm{NT}$ das silagens de milho Table 5 - $\quad \mathrm{pH}$ index and $\mathrm{N}-\mathrm{NH}_{3} / \mathrm{NT}$ of corn silages

\begin{tabular}{|c|c|c|c|c|c|c|}
\hline \multirow[t]{2}{*}{$\begin{array}{l}\text { Estrato } \\
\text { Stratum }\end{array}$} & \multirow[t]{2}{*}{$\begin{array}{c}\text { Tamanho de partícula } \\
\text { Particle size }\end{array}$} & \multirow[t]{2}{*}{$\begin{array}{l}\text { Altura de corte } \\
\text { Cutting height }\end{array}$} & \multicolumn{4}{|c|}{$\begin{array}{l}\text { Período de desensilagem } \\
\text { Feed-out period }\end{array}$} \\
\hline & & & $\begin{array}{c}24 / 8 \text { a } 14 / 9 \\
8 / 24 \text { to } 9 / 14\end{array}$ & $\begin{array}{l}15 / 9 \text { a } 5 / 10 \\
9 / 15 \text { to } 10 / 5\end{array}$ & $\begin{array}{c}6 / 10 \text { a } 26 / 10 \\
10 / 6 \text { to } 10 / 26\end{array}$ & $\begin{array}{r}27 / 10 \text { a } 16 / 11 \\
10 / 27 \text { to } 11 / 16\end{array}$ \\
\hline & & & \multicolumn{4}{|c|}{$\mathrm{N}-\mathrm{NH}_{3} / \mathrm{NT}, \%$} \\
\hline & Pequena (Small) & Baixa (Low) & 2,74 & 2,13 & 2,64 & 2,55 \\
\hline Inferior & Grande (Large) & Baixa (Low) & 2,73 & 2,37 & 1,96 & 1,46 \\
\hline \multirow[t]{3}{*}{ Inferior } & Pequeno (Small) & Alta (High) & 2,73 & 2,44 & 2,51 & 1,96 \\
\hline & Grande (Large) & Alta (High) & 2,08 & 2,34 & 2,72 & 1,52 \\
\hline & Média (Mean) & & 2,57 & 2,32 & 2,43 & 1,87 \\
\hline & Pequeno (Small) & Baixa (Low) & 2,94 & 3,09 & 2,84 & 3,20 \\
\hline Superior & Grande (Large) & Baixa (Low) & 2,62 & 2,41 & 2,56 & 2,24 \\
\hline \multirow[t]{5}{*}{ Superior } & Pequeno (Small) & Alta (High) & 3,14 & 3,29 & 3,27 & 3,20 \\
\hline & Grande (Large) & Alta (High) & 2,86 & 2,33 & 1,90 & 2,34 \\
\hline & Média (Mean) & & 2,89 & 2,78 & 2,64 & 2,73 \\
\hline & Média dos períodos & an of periods) & 2,73 & 2,55 & 2,54 & 2,30 \\
\hline & \multicolumn{6}{|c|}{ Equação regressão: $\mathrm{N}^{-\mathrm{NH}_{3}} / \mathrm{NT}=2,54\left(\mathrm{R}^{2}: 0,3832 ; \mathrm{CV}: 33,13 \% ; \mathrm{P}=0,3870\right)$} \\
\hline \multirow{6}{*}{ Inferior } & & & \multicolumn{4}{|c|}{$\mathrm{pH}$, valores $(\mathrm{pH}$, value $)$} \\
\hline & Pequeno (Small) & Baixa (Low) & 3,63 & 4,05 & 4,00 & 4,22 \\
\hline & Grande (Large) & Baixa (Low) & 3,70 & 4,03 & 4,09 & 4,18 \\
\hline & Pequeno (Small) & Alta (High) & 3,59 & 3,90 & 4,06 & 4,09 \\
\hline & Grande (Large) & Alta (High) & 3,68 & 3,92 & 4,17 & 4,29 \\
\hline & Média (Mean) & & 3,65 & 3,97 & 4,08 & 4,19 \\
\hline \multirow{6}{*}{ Superior } & Pequeno (Small) & Baixa (Low) & 3,73 & 4,06 & 3,99 & 4,43 \\
\hline & Grande (Large) & Baixa (Low) & 3,74 & 3,87 & 4,31 & 4,31 \\
\hline & Pequeno (Small) & Alta (High) & 3,82 & 3,96 & 4,09 & 4,09 \\
\hline & Grande (Large) & Alta (High) & 3,87 & 4,09 & 4,37 & 4,48 \\
\hline & Média (Mean) & & 3,79 & 3,99 & 4,19 & 4,33 \\
\hline & Média dos períodos & an of periods) & 3,72 & 3,98 & 4,13 & 4,26 \\
\hline
\end{tabular}

Equação regressão: $\mathrm{pH}=3,5802+0,0085 \mathrm{D}\left(\mathrm{R}^{2}:\right.$ 0,5251; $\mathrm{CV}: 4,75 \%$; $\left.\mathrm{P}<0,0001\right)$

${ }^{*} \mathrm{D}=$ período de desensilagem de 1 a 84 dias ( $D=$ Feed-out period of 1 to 84 days).

A deterioração das silagens de milho ocorreu em diferentes velocidades conforme a composição química da silagem, em decorrência da elevação da temperatura e do $\mathrm{pH}$ durante a desensilagem (Tabelas 4 e 5).

As variáveis temperatura (TS), diferencial de temperatura entre a silagem e o ambiente (DTSA), $\mathrm{pH}$ e N-NH$/ 2 / \mathrm{NT}$ diferiram estatisticamente $(\mathrm{P}<0,05)$ na comparação entre silagens nos estratos do silo (Tabela 6). A silagem contida no estrado superior do silo, independentemente da altura de colheita e do tamanho de partículas, apresentou maiores valores de TS $\left(29,14\right.$ vs $\left.26,84^{\circ} \mathrm{C}\right)$, DTSA $\left(8,22\right.$ vs $\left.5,93^{\circ} \mathrm{C}\right), \mathrm{pH}$ $(4,08$ vs 3,97$)$ e N-NH 3 /NT (2,77 vs $2,31 \%)$ em comparação àquela contida ao estrato inferior do silo de armazenamento.

Verificou-se efeito da interação altura de colheita $\times$ tamanho de partícula sobre a TS, DTSA e o pH (Tabela 7). Maiores TS e DTSA, respectivamente, foram observadas em silagens com tamanho de partículas grandes e altura de corte de $15,2 \mathrm{~cm}\left(29,50\right.$ e $\left.8,53^{\circ} \mathrm{C}\right)$ e $38,6 \mathrm{~cm}\left(29,70\right.$ e $\left.8,80^{\circ} \mathrm{C}\right)$ em relação àquelas com partículas pequenas e altura de corte de $15,2 \mathrm{~cm}\left(27,06\right.$ e $\left.6,15^{\circ} \mathrm{C}\right)$ e $38,6 \mathrm{~cm}\left(25,71\right.$ e $\left.4,81^{\circ} \mathrm{C}\right)$.

Avaliando a estabilidade aeróbia de silagens de capimelefante emurchecido e inoculado, Guim et al. (2002) observaram diferenças significativas $(\mathrm{P}<0,05)$ nos valores de $\mathrm{pH}$ no 8 o dia de exposição aeróbia. Segundo esses autores, o valor de $\mathrm{pH}$, se considerado isoladamente, pode se tornar um parâmetro de qualidade de silagens de pequena valia, pois geralmente acompanha as mudanças no conteúdo de $\mathrm{N}-\mathrm{NH}_{3}$ e ácidos orgânicos. Senger et al. (2005) verificaram que o $\mathrm{pH}$ da silagem de milho é influenciado pelo nível de compactação da massa ensilada e apresenta maior valor em condições de má compactação $\left(300 \mathrm{~kg} / \mathrm{m}^{3}\right.$ de MV).

Neste trabalho os menores valores de $\mathrm{pH}(\mathrm{P}<0,05)$ foram observados nas silagens com tamanho de partículas pequenas e alturas de corte de $38,6 \mathrm{~cm}(3,95)$ e 15,2 cm (4,01), no entanto, esses valores não diferiram estatisticamente dos obtidos na silagem com tamanho de partículas grandes 
Tabela 6 - Diferencial de temperatura entre silagem e ambiente (DTSA), temperatura (TS), $\mathrm{pH}$ e $\mathrm{N}-\mathrm{NH}_{3} / \mathrm{NT}$

Table 6 - Temperature difference between silage and environment (TDSE), temperature (ST), $\mathrm{pH}$ index, and $\mathrm{N}-\mathrm{NH}_{3} / \mathrm{NT}$

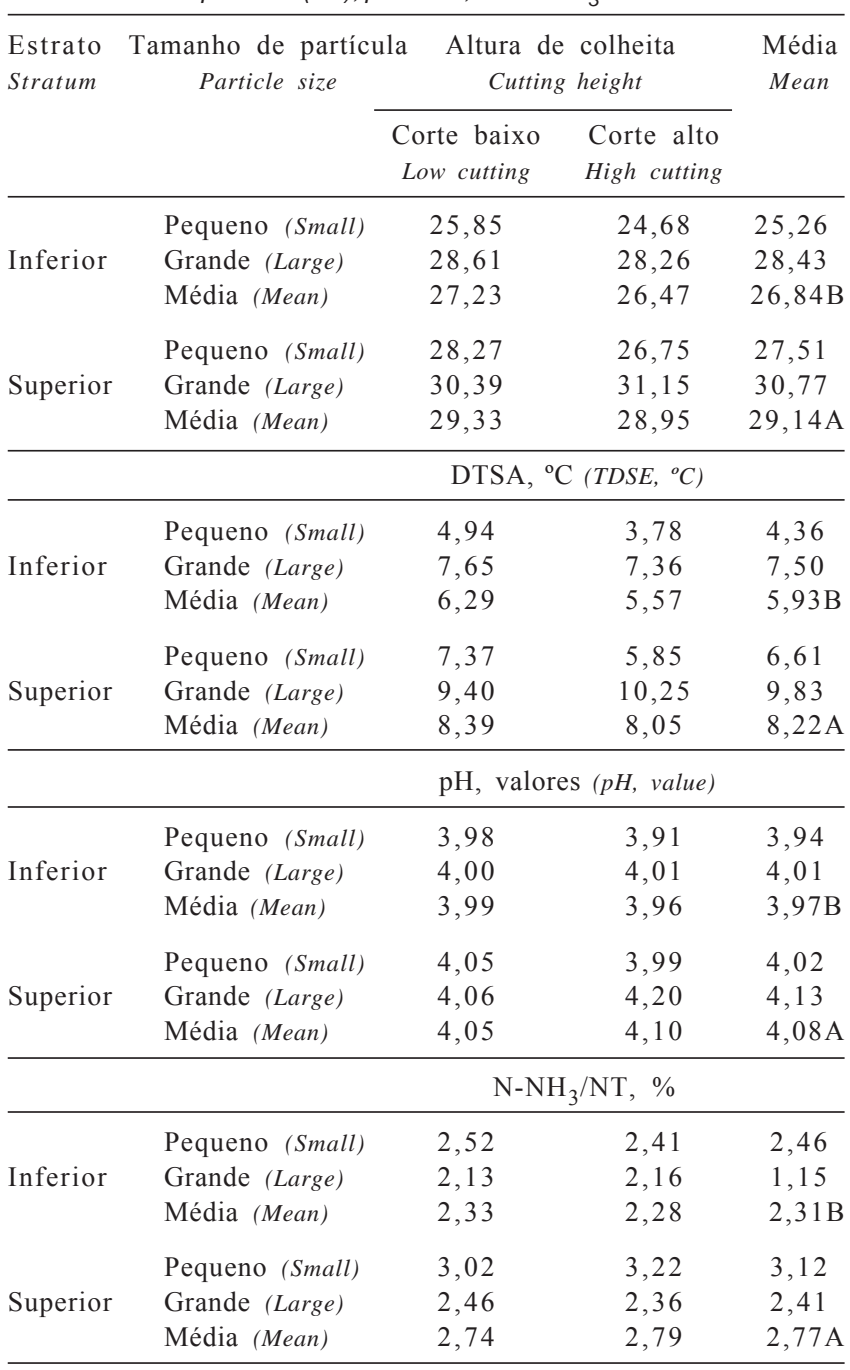

Médias na coluna seguidas de letras maiúsculas diferentes diferem $(P<0,05)$ pelo teste $F$.

Means within a column followed by different capital letters are different $(P<0.05)$ by $F$ test.

e altura de corte de $15,2 \mathrm{~cm}(4,03)$ em relação à silagem de partículas grandes e altura de corte de $38,6 \mathrm{~cm}(4,10)$.

As perdas após a abertura do silo estão associadas ao manejo imposto na utilização da silagem. Quanto maior a taxa de retirada de material do silo, menores as perdas e, quanto maior a movimentação da massa ensilada, maior a deterioração do painel do silo. Entretanto, a extensão de deterioração do material após a abertura do silo está associada à estabilidade aeróbia da silagem. Segundo Evangelista etal.(2004), a estabilidade aeróbia da silagem, conceitualmente, pode ser avaliada como o tempo de resistência da massa de silagem à degradação após a retirada do silo, ou ainda, conforme Taylor \& Kung Jr. (2002), como o tempo para que a silagem atinja temperaturas superiores a $2^{\circ} \mathrm{C}$ em relação à temperatura ambiente.
A estabilidade da silagem é determinada pela degradação aeróbia (pós-fermentação), resultante do desenvolvimento de fungos e leveduras, que ocorre após abertura do silo. A degradação aeróbia é mais intensa quanto melhor a qualidade da silagem, em virtude dos maiores teores de carboidratos solúveis e de ácido lático residuais.

Resultados de pesquisa evidenciam que silagens adicionadas de fontes de carboidratos não-estruturais apresentam menor estabilidade aeróbia na desensilagem (Keady \& Steen, 1995), o que está relacionado ao seu maior teor de ácido láctico, uma vez que os microrganismos aeróbios degradam-no com facilidade após a abertura do silo, gerando $\mathrm{CO}_{2}$, etanol e ácido acético, além de calor. A presença de $\mathrm{O}_{2}$ decorrente da entrada de ar por ocasião da abertura do silo, do tempo de estocagem do material e durante a desensilagem proporciona ambiente favorável ao crescimento de microrganismos aeróbios. Esses microrganismos utilizam vários substratos derivados diretamente da forragem ou indiretamente da fermentação (Guim et al., 2002), alterando as características qualitativas do material e/ou provocando perdas de nutrientes do material na desensilagem.

Segundo Licitra et al. (1996), o aumento do tempo e da temperatura durante a desensilagem gera perdas por reações de oxidação e proteólise na massa. A proteólise pode aumentar a solubilidade da proteína pela ação microbiana quando há utilização do nitrogênio solúvel para uso em seu crescimento. Na presença de oxigênio, microrganismos como as bactérias, seguidas por leveduras, bolores e fungos, provocam alterações qualitativas significativas na massa ensilada. A colonização desses microrganismos é determinada pelo substrato disponível ao seu consumo.

O comportamento diferenciado da temperatura nos silos (Tabelas 5 e 6 ) pode ser resultado da disponibilidade de compostos solúveis nos diferentes estratos. Esse parâmetro está relacionado diretamente à atividade microbiana. Entretanto, a atividade microbiana não depende somente da disponibilidade de compostos solúveis, mas também do grau de compactação da massa (Tabelas 1 e 2), pois, quando submetidas a condições de aerobiose, as maiores compactações dificultam a entrada de oxigênio na massa. As silagens bem conservadas, em plenas condições de anaerobiose e com elevadas compactações (superior a $700 \mathrm{~kg} / \mathrm{m}^{3} \mathrm{de} \mathrm{MV}$ ), segundo Nussio (1995), não proporcionam a produção de ácido butírico e restringem a produção de ácido acético, porém, favorecem a instabilidade aeróbia da silagem causada pela grande concentração de ácido lático. O sucesso da estabilidade da silagem é o equilíbrio entre a participação de ácido acético em associação ao ácido lático. A assimilação aeróbica de lactato da silagem por fungos, leveduras e Bacillus diminui o potencial de 
Tabela 7 - Diferencial de temperatura entre silagem e ambiente, temperatura, $\mathrm{pH}$ e $\mathrm{N}-\mathrm{NH}_{3} / \mathrm{NT}$ de silagens de milho colhido com diferentes tamanhos de partícula e alturas de corte

Table 7 - $\quad$ Temperature different between silage and environment (TDSE), temperature (ST), $\mathrm{pH}$ index and $\mathrm{N}-\mathrm{NH}_{3} / \mathrm{NT}$ of corn silages, based on particle size and cutting height

\begin{tabular}{lcc}
\hline $\begin{array}{l}\text { Tamanho de partícula } \\
\text { Particle size }\end{array}$ & $\begin{array}{c}\text { Altura de colheita } \\
\text { Cutting height }\end{array}$ & $\begin{array}{c}\text { Média } \\
\text { Mean }\end{array}$ \\
\cline { 2 - 3 } & Corte baixo & Corte alto \\
& Low cutting & High cutting \\
\hline
\end{tabular}

$\mathrm{TS},{ }^{\circ} \mathrm{C}\left(S T,{ }^{\circ} \mathrm{C}\right)$

\begin{tabular}{llll} 
Pequeno (Small) & $27,06 \mathrm{~b}$ & $25,71 \mathrm{~b}$ & 26,38 \\
Grande (Large) & $29,50 \mathrm{a}$ & $29,70 \mathrm{a}$ & 29,60 \\
Média (Mean) & 28,28 & 27,70 & \\
\hline
\end{tabular}

DTSA, ${ }^{\circ} \mathrm{C}\left(\right.$ TDSE, $\left.{ }^{\circ} \mathrm{C}\right)$

\begin{tabular}{llll} 
Pequeno (Small) & $6,15 \mathrm{~b}$ & $4,81 \mathrm{~b}$ & 5,48 \\
Grande (Large) & $8,53 \mathrm{a}$ & $8,80 \mathrm{a}$ & 8,66 \\
Média (Mean) & 7,34 & 6,80 & \\
\hline & $\mathrm{pH}$, valor (pH, value) & \\
Pequeno (Small) & $4,01 \mathrm{ab}$ & $3,95 \mathrm{~b}$ & 3,98 \\
Grande (Large) & $4,03 \mathrm{ab}$ & $4,10 \mathrm{a}$ & 4,06 \\
Média (Mean) & 4,02 & 4,02 & \\
\hline & $\mathrm{N}-\mathrm{NH}_{3} / \mathrm{NT}, \%$ & \\
& & & \\
Pequeno (Small) & 2,77 & 2,81 & $2,79 \mathrm{~A}$ \\
Grande (Large) & 2,30 & 2,26 & $2,28 \mathrm{~B}$ \\
Média (Mean) & $2,53 \mathrm{~A}$ & $2,53 \mathrm{~A}$ & \\
\hline
\end{tabular}

Médias seguidas de letras minúsculas diferentes diferem $(P<0,05)$ pelo teste Tukey.

Médias na linha ou na coluna seguidas por letras maiúsculas diferentes diferem $(P<0,05)$ pelo teste $F$.

Means, followed by different small letters, are different $(P<.05)$ by Tukey test.

Means within row or column followed by different capital letters are different $(P<.05)$ by F test.

conservação em virtude da conversão aeróbica de lactato a acetato ou da degradação anaeróbica de lactato a ácido butírico ou acético, com conseqüente elevação do $\mathrm{pH}$.

A abertura dos silos e a desestruturação diária da massa ensilada para fornecimento aos animais causaram maior permeabilidade a entrada de oxigênio na massa, causando alterações na composição das silagens. Essas alterações foram acompanhadas de aumento nos valores de $\mathrm{pH}$, temperatura e nitrogênio amoniacal (Tabelas 3 e 4), ocasionado pela oxidação da massa e pela atividade de microrganismos aeróbios.

As perdas da silagem ocorrem via $\mathrm{CO}_{2}$ pela ação dos microrganismos aeróbios e pela oxidação da matéria orgânica. Segundo Nussio (1995), a exposição da silagem ao ar após a abertura e durante o fornecimento é ocasionalmente acompanhada por deterioração aeróbica da silagem e resulta em perdas econômicas em virtude das perdas de MS e de energia.

\section{Conclusões}

Partículas de tamanho pequeno determinam maior eficiência de compactação da massa ensilada, diminuindo gradientes de temperatura e $\mathrm{pH}$ na desensilagem de silagens produzidas a partir de partículas grandes. Maior deterioração das silagens de milho ocorre no estrato superior do silo, em virtude da elevação da temperatura e dos maiores valores de $\mathrm{pH}$ e nitrogênio amoniacal em relação ao estrato inferior. O diferencial de temperatura entre silagem e ambiente ocorreu em maior proporção no estrato superior do silo, o que está diretamente relacionado ao tempo de desensilagem, decorrente da menor eficiência de compactação, o que determinou aumento no teor de nitrogênio amoniacal e elevação dos valores de $\mathrm{pH}$ da silagem, indicando alteração no valor nutritivo.

\section{Literatura Citada}

ASSOCIATION OF OFFICIAL ANALYTICAL CHEMISTS - AOAC. Official methods of analysis. 16.ed. Washington, D.C.: AOAC, 1995. 2000p.

BALSALOBRE, M.A.A.; NUSSIO, L.G.; MARTHA JR., G.B Controle de perdas na produção de silagens de gramíneas tropicais. In: REUNIÃO ANUAL DA SOCIEDADE BRASILEIRA DE ZOOTECNIA, 38., 2001, Piracicaba. Anais... Piracicaba: Sociedade Brasileira de Zootecnia, 2001. p.890-911.

EVANGElistA, A.R.; ABREU, J.G.; PEREIRA, R.C. Perdas na conservação de forragens. In: SIMPÓSIO SOBRE PRODUÇÃO E UTILIZAÇÃO DE FORRAGENS CONSERVADAS, 2., 2004, Maringá. Anais... Maringá: Universidade Estadual de Maringá, 2004. p.75-112.

GUIM, A.; ANDRADE, P.; ITURRINO-SCHOCKEN, R.P. et al. Estabilidade aeróbica de silagens de Capim-elefante (Pennisetum purpureum, Schum) emurchecido e tratado com inoculante microbiano1. Revista Brasileira de Zootecnia, v.31, n.6, p.2176-2185, 2002.

HILL, J.; LEAVER, J.D. Changes in chemical composition and nutritive value of urea treated whole crop wheat during exposure to air. Animal Feed Science and Technology, v.66, p.181195, 2002.

KEADY, T.W.; STEEN, R.W.J. The effects of treating low drymatter, low digestibility grass with a bacterial inoculant on the intake and performance of beef cattle, and studies on its mode of action. Grass and Forage Science, v.50, p.217226, 1995.

LEIBENSPERGER, P.Y.; PITT, R.E. A model of clostridial dominance in silage. Grass and Forrage Science, v.42, n.3, p.297-317, 1987.

LICITRA, G.; HERNÁNDEZ, T.M.; van SOEST, P.J. Standardization of procedures for nitrogen fractionation of ruminant feeds. Animal Feed Science Technology, v.57, p.347-358, 1996.

LOURES, D.R.S.; GARCIA, R.; PEREIRA, O.G. et al. Características do efluente e composição químico-bromatológica da silagem de capim-elefante sob diferentes níveis de compactação. Revista Brasileira de Zootecnia, v.32, n.6, p.1851-1858, 2003 (supl. 2).

McDONALD, P.; HENDERSON, N.; HERON, S. The biochemistry of silage. 2.ed. Marlow: Chalcombe, 1991. 339p.

MUCK, R.E. Factors influencing silage quality e their implications form management. Jornal of Dairy Science, v.71, p.29923002, 1988. 
MUHLBACH, P.R.F. Silagem: produção com controle de perdas. In: LOBATO, J.F.P.; BARCELOS, J.O.J.; HESSLER, A.M. (Eds.) Produção de bovinos de corte. Porto Alegre: Pontifícia Universidade Católica, 1999. p.97-120.

MULligAN, F.J.; QUIRKE, J.; RATH, M. et al. Intake, digestibility, milk production and kinetics of digestión and pasaje for diets based on maize or grass silage fed to late lactation dairy cows. Livestock Production Science, v.74, p.113-124, 2002.

NEUMANN, M.; RESTLE, J.; ALVES FILHO, D.C. et al. Avaliação de diferentes híbridos de sorgo (Sorghum bicolor, L. Moench) quanto aos componentes da planta e silagens produzidas. Revista Brasileira de Zootecnia, v.31, n.1, p.302-312, 2002a (supl. 1).

NEUMANN, M.; RESTLE, J.; ALVES FILHO, D.C. et al. Avaliação do valor nutritivo da planta e da silagem de diferentes híbridos de sorgo (Sorghum bicolor, L. Moench). Revista Brasileira de Zootecnia, v.31, n.1, p.293-301, 2002b (supl. 1).

NUSSIO, L.G. Milho e sorgo para produção de silagem. In: PEIXOTO, A.M.; MOURA, J.C.; FARIA, V.P. (Eds.) Volumosos para bovinos. 2.ed. Piracicaba: Fundação de Estudos Agrários Luiz de Queiroz, 1995. p.75-177.

NUSSIO, L.G.; CAMPOS, F.P.; DIAS, F.N. Importância da qualidade da porção vegetativa no valor alimentício da silagem de milho. In: SIMPÓSIO SOBRE PRODUÇÃO E UTILIZAÇÃO DE FORRAGENS CONSERVADAS, 2001, Maringá. Anais... Maringá: Universidade Estadual de Maringá, 2001. p.127-145.

NUSSIO, L.G.; PAZIANI, S.F.; NUSSIO, C.M.B. Ensilagem de capins tropicais. In: REUNIÃO ANUAL DA SOCIEDADE BRASILEIRA DE ZOOTECNIA, 39., Recife, 2002. Palestras... Recife: Sociedade Brasileira de Zootecnia, 2002. p.60-94.
RECOMENDAÇÕES DA COMISSÃO DE FERTILIDADE DO SOLO - RS/SC. Recomendações de adubação e calagem para os Estados do Rio Grande do Sul e Santa Catarina. 3.ed. Passo Fundo: SBCS-Núcleo Regional Sul: EMBRAPACNPT, 1995. 223p.

STATISTICAL ANALYSIS SYSTEM - SAS. User's guide: statistics, version 6. 4.ed. Cary: 1993. v.2, 943p.

SENGER, C.C.D.; MUHLBACH, P.R.F.; SÁNCHEZ, L.M.B. et al. Composição química e digestibilidade "in vitro" de silagem de milho com distintos teores de umidade e níveis de compactação. Ciência Rural, v.35, n.6, p.1393-1399, 2005.

TAYLOR, C.C.; KUNG JR., L. The effect of Lactobacillus buchnery 40788 on the fermentation and aerobic stability of high moisture corn in laboratory silos. Journal of Dairy Science, v. 85, p.1526-1532, 2002.

TOSI, P.; MATTOS, W.R.S. ; TOSI, H. et al. Avaliação do capimelefante (Pennisetum purpureum, Schum.) cultivar Taiwan A148, ensilado com diferentes técnicas de redução de umidade. Revista Brasileira de Zootecnia, v.28, n.5, p.947-954, 1999.

WILLIAMS, A.G.; HOXEY, R.P.; LOWE, J.F. Changes in temperature and silo gas composition during ensiling, storage and feeding-out grass silage. Grass and Forage Science, v.52, p.176-189, 1997. 